Prospects for High Energy Resolution Gamma Ray Spectroscopy with Europium-Doped Strontium lodide

N. J. Cherepy, S. A. Payne, R. Hawrami, A. Burger, L. Boatner, E. Van Loef, K. Shah

April 6, 2009

Proceedings of the Materials Research Society 
This document was prepared as an account of work sponsored by an agency of the United States government. Neither the United States government nor Lawrence Livermore National Security, LLC, nor any of their employees makes any warranty, expressed or implied, or assumes any legal liability or responsibility for the accuracy, completeness, or usefulness of any information, apparatus, product, or process disclosed, or represents that its use would not infringe privately owned rights. Reference herein to any specific commercial product, process, or service by trade name, trademark, manufacturer, or otherwise does not necessarily constitute or imply its endorsement, recommendation, or favoring by the United States government or Lawrence Livermore National Security, LLC. The views and opinions of authors expressed herein do not necessarily state or reflect those of the United States government or Lawrence Livermore National Security, LLC, and shall not be used for advertising or product endorsement purposes. 


\title{
Prospects for High Energy Resolution Gamma Ray Spectroscopy with Europium-Doped Strontium Iodide
}

Nerine Cherepy and Stephen A. Payne, Lawrence Livermore National Laboratory, Livermore, CA 94550

Rastgo Hawrami and Arnold Burger, Fisk University, Nashville, TN 37208

Lynn Boatner, Oak Ridge National Laboratory, Oak Ridge, TN 37831

Edgar Van Loef and Kanai Shah, Radiation Monitoring Devices, Watertown, MA 02472

\begin{abstract}
Europium-doped strontium iodide scintillators offer a light yield exceeding 100,000 photons/MeV and excellent light yield proportionality, while at the same time, $\mathrm{SrI}_{2}$ is readily grown in single crystal form. Thus far, our collaboration has demonstrated an energy resolution with strontium iodide of $2.6 \%$ at $662 \mathrm{keV}$ and $7.6 \%$ at $60 \mathrm{keV}$, and we have grown single crystals surpassing $30 \mathrm{~cm}^{3}$ in size (with lower resolution). Our analysis indicates that $\mathrm{SrI}_{2}(\mathrm{Eu})$ has the potential to offer $2 \%$ energy resolution at $662 \mathrm{keV}$ with optimized material, optics, and read-out. In particular, improvements in feedstock purity may result in crystal structural and chemical homogeneity, leading to improved light yield uniformity throughout the crystal volume, and consequently, better energy resolution. Uniform, efficient light collection and detection, is also required to achieve the best energy resolution with a $\mathrm{SrI}_{2}(\mathrm{Eu})$ scintillator device.
\end{abstract}

\section{INTRODUCTION}

False alarms in radioisotope identification instrumentation often derive from inadequate energy resolution of the gamma ray spectrometers used. Meanwhile, detection events may be missed altogether if the detectors are too small. For these reasons, we are developing new scintillator materials offering high resolution that are growable in large volumes. Alkaline earth halides are a class of scintillators that appear promising with regards to materials cost, growth, and scintillation yields [1-4]. We have recently found that single crystal divalent Eu-doped Strontium Iodide yields $>100,000$ photons/MeV in the $\mathrm{Eu}^{2+}$ luminescence band (435 nm central wavelength), with a decay time of $\sim 1.2 \mu \mathrm{s}$, and excellent light yield proportionality (and hence intrinsic energy resolution) that is superior to that of Ce-doped lanthanum bromide [5-9]. An ongoing coordinated effort between Fisk University, Oak Ridge National Laboratory, Radiation Monitoring Devices, and Lawrence Livermore National Laboratory seeks to improve Strontium Iodide crystal growth and the performance of prototype detectors, with a device goal of $2 \%$ resolution at $662 \mathrm{keV}$ and a crystal size of 3” in length by 3” in diameter.

\section{EXPERIMENT}

Eu-doped strontium iodide crystals were grown by the vertical Bridgman technique at Fisk University, Radiation Monitoring Devices, and Oak Ridge National Laboratory. Beta-induced luminescence spectra were acquired using a Sr-90/Y-90 ( 1 MeV) source, that is expected to be equivalent to that produced by gamma excitation. Gamma ray spectroscopy was performed by 
optically coupling the crystals with mineral oil to a Hamamatsu R6231-100 PMT (QE at $435 \mathrm{~nm}$ of 32\%) PMT and wrapping with Teflon reflector materials. The signals from the PMT anode were shaped with a Tennelec TC 244 spectroscopy amplifier (8 $\mu$ s shaping time) and recorded with an Amptek MCA8000-A multi-channel analyzer; or by interfacing with a Bridgeport Instruments eMorpho digitizer/multi-channel analyzer.

\section{RESULTS AND DISCUSSION}

Small crystals $\left(<1 \mathrm{~cm}^{3}\right)$ of $\operatorname{SrI}_{2}(\mathrm{Eu})$ have been found to provide an energy resolution at 662 $\mathrm{keV}$ of 2.5-2.8\% [6-9]. Figure 1 shows a small crystal of $\mathrm{SrI}_{2}(\mathrm{Eu})$ offering $662 \mathrm{keV}$ energy resolution comparable to that of $\mathrm{LaBr}_{3}(\mathrm{Ce})$. Figure 2 shows the energy resolution acquired with a Ba-133 source, indicating resolution for $\mathrm{SrI}_{2}(\mathrm{Eu})$ that is markedly superior to that of $\mathrm{LaBr}_{3}(\mathrm{Ce})$ in the lower energy region (Ba-133 main gamma rays are at 81, 276.4, 302.9, 356 and 383.9 keV; some lower energy x-rays appear in the spectrum, as well).

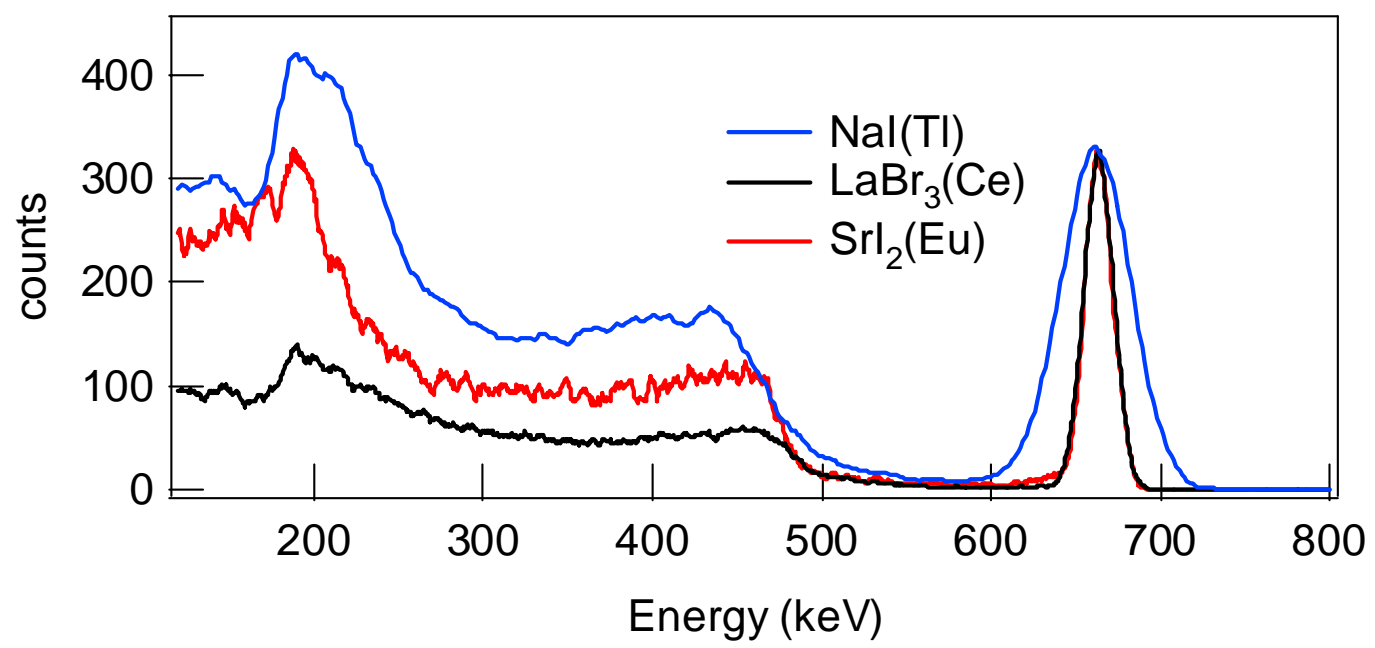

Figure 1. Pulse-height spectra acquired at $662 \mathrm{keV}$ with a $\sim 0.5 \mathrm{~cm}^{3} \operatorname{SrI}_{2}(5 \% \mathrm{Eu})$ crystal grown at Fisk University, along with spectra acquired with a St. Gobain $\operatorname{LaBr}_{3}(\mathrm{Ce})$ crystal and a St. Gobain NaI(Tl) crystal.

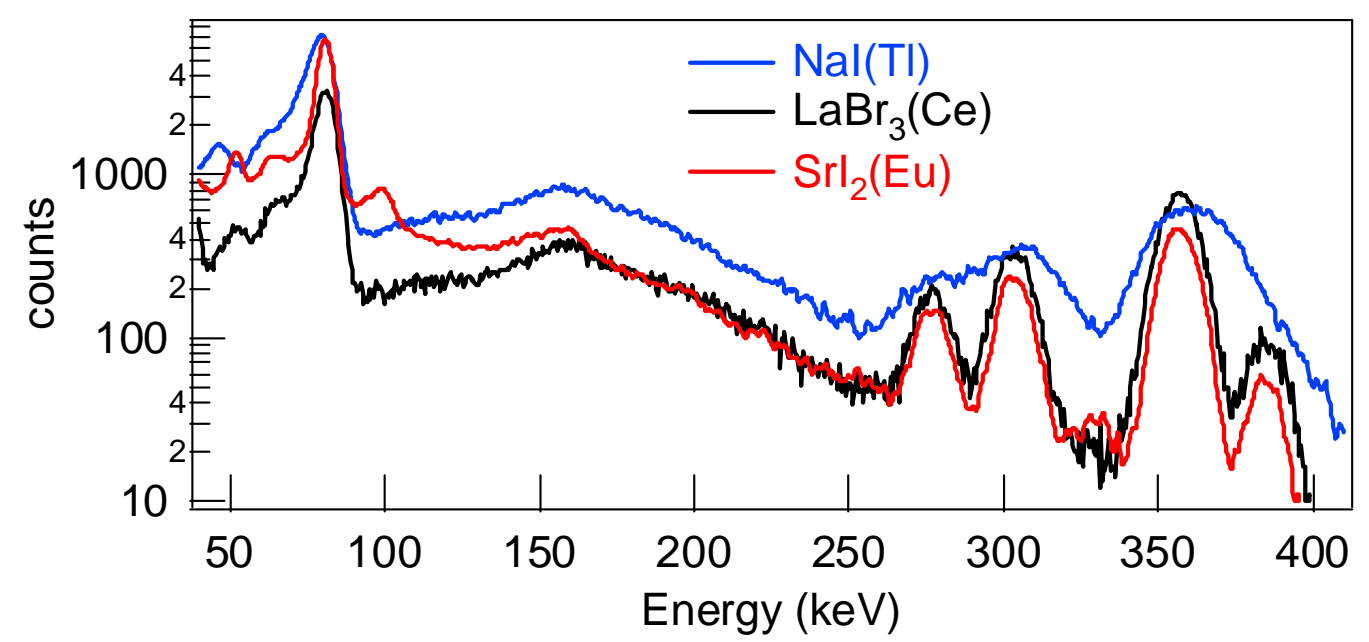

Figure 2. Gamma ray spectra of the same crystals used for Fig. 1, acquired with a ${ }^{133}$ Ba source. 
A plot of energy resolution as a function of gamma energy shown in Figure 3 indicates that the resolution of $\mathrm{SrI}_{2}(\mathrm{Eu})$ is excellent in the low energy region, but is not as good as would be predicted by a simple fit to Poisson statistics at higher gamma energies; an offset, "b" must be added for a good fit to the data. It may be that this energy resolution degradation is due to inhomogeneity of the light yield response, and this is currently being investigated. Assuming the inhomogeneity is due to material non-uniformity, we expect to be able to obtain improved energy resolution, as shown by the blue line $(b=0)$. The energy resolution at $662 \mathrm{keV}$ for $\mathrm{SrI}_{2}(\mathrm{Eu})$ would be $2.3 \%$, if the non-uniformity can be eliminated. Table 1 compares the properties of $\mathrm{SrI}_{2}(\mathrm{Eu})$ and $\mathrm{LaBr}_{3}(\mathrm{Ce})$.

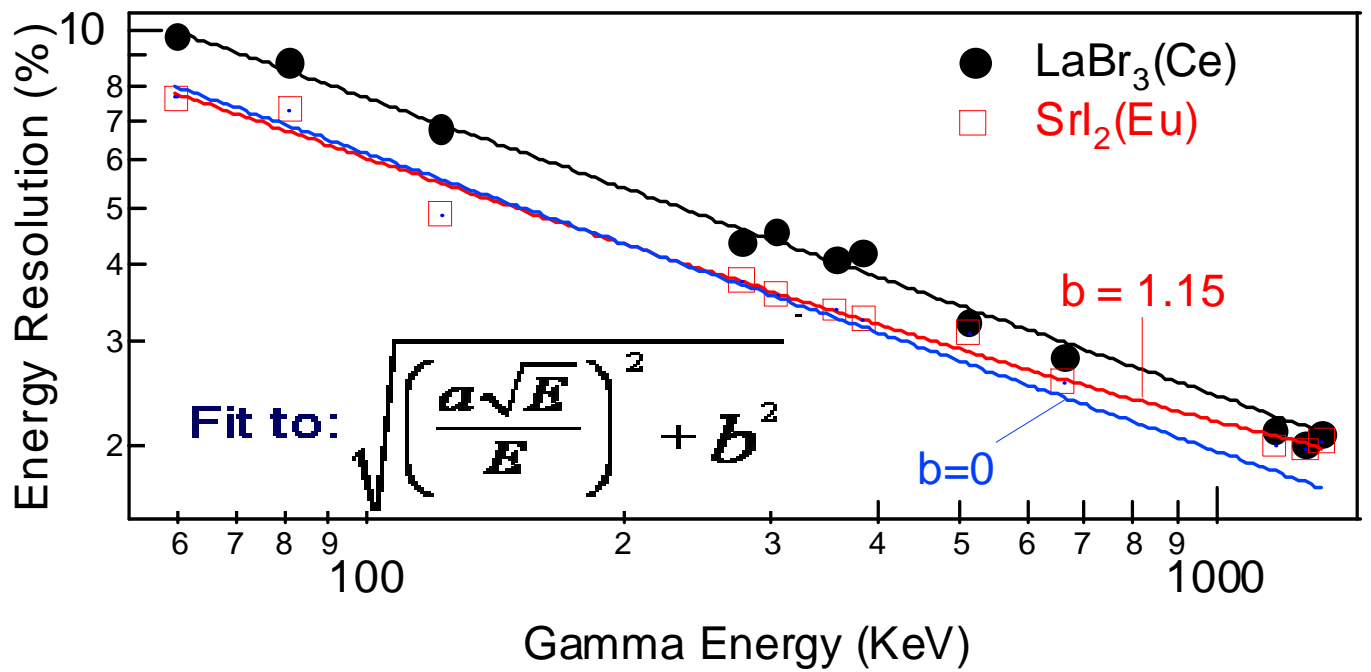

Figure 3. The energy resolution as a function of gamma ray energy for $\mathrm{SrI}_{2}(\mathrm{Eu})$ and $\mathrm{LaBr}_{3}(\mathrm{Ce})$ using Ba-133, Am-241, Co-57, Na-22, Co-60, and Cs-137 sources. Fits to Poisson statistics (plus an offset, b) are shown. For $\operatorname{LaBr}_{3}(\mathrm{Ce}), \mathrm{b}=0$, while $\mathrm{SrI}_{2}(\mathrm{Eu})$ requires $\mathrm{b}=1.15$.

Table 1. Comparison of the properties of $\mathrm{SrI}_{2}(\mathrm{Eu})$ and $\mathrm{LaBr}_{3}(\mathrm{Ce})$ scintillator crystals.

\begin{tabular}{|l|l|l|l|}
\hline Property & $\mathbf{L a B r}_{3}(\mathbf{C e})$ & $\mathbf{S r I}_{2}(\mathbf{E u})$ & Comparison \\
\hline Melting Point & $783^{\circ} \mathrm{C}$ & $538{ }^{\circ} \mathrm{C}$ & Less thermal stress \\
\hline Handling & Easily cleaves & Resists cleavage & Better processing \\
\hline Light Yield & $60,000 \mathrm{Ph} / \mathrm{MeV}$ & $100,000 \mathrm{Ph} / \mathrm{MeV}$ & Higher \\
\hline Radioactivity & $\mathrm{La}$ intrinsic backgd & None & Less noise \\
\hline $\begin{array}{l}\text { Gamma absorption } \\
(2 x 3 ”, 662 \mathrm{keV})\end{array}$ & $22 \%$ & $24 \%$ & Similar \\
\hline $\begin{array}{l}\text { Energy Resolution } \\
(662 \mathrm{keV})\end{array}$ & $2.6 \%$ (realized) & $2.6 \%$ (realized) & $\begin{array}{l}\text { Better with uniform } \\
\text { crystals }\end{array}$ \\
\hline $\begin{array}{l}\text { Proportionality } \\
\text { contribution }\end{array}$ & $1.6 \%$ & $1.2 \%$ & Favorable \\
\hline $\begin{array}{l}\text { Inhomogeniety } \\
\text { contribution }\end{array}$ & $0 \%$ & $1.2 \%$ (current) & Needs development \\
\hline
\end{tabular}


In addition to the analysis of the data shown in Figure 3, further evidence that the crystal homogeneity should be improved in order to realize the best energy resolution with $\operatorname{SrI}_{2}(\mathrm{Eu})$ is our finding that zone-refined $\mathrm{SrI}_{2}$ feedstock produces the crystals with the best resolution. Of the 2-5 $\mathrm{cm}^{3}$ crystals grown by our collaboration, those grown from zone-refined $\mathrm{SrI}_{2}$ feedstock exhibit the best resolution.

Figure 4 shows how scintillator detectors may be optimized optically by use of a highly reflective Teflon wrapping material from Gore [10]. A $\sim 2 \mathrm{~cm}^{3} \operatorname{SrI}_{2}(4 \% \mathrm{Eu})$ crystal was wrapped, first with St. Gobain Teflon tape, in a tent-like wrapping style, yielding energy resolution of $5.8 \%$ at $662 \mathrm{keV}$. The same crystal was re-wrapped with Teflon tape, tightly around the annulus and top, yielding 3.3\% resolution. Finally, the crystal was wrapped with Gore DRP $1 \mathrm{~mm}$ material, producing 3.1\% resolution at $662 \mathrm{keV}$. Thus, we find that the absolute reflectivity and uniformity of the reflector wrapping is important in attaining the best energy resolution for a given crystal. We have performed more extensive experiments exploring crystal geometry and wrapping materials that are reported elsewhere [10].

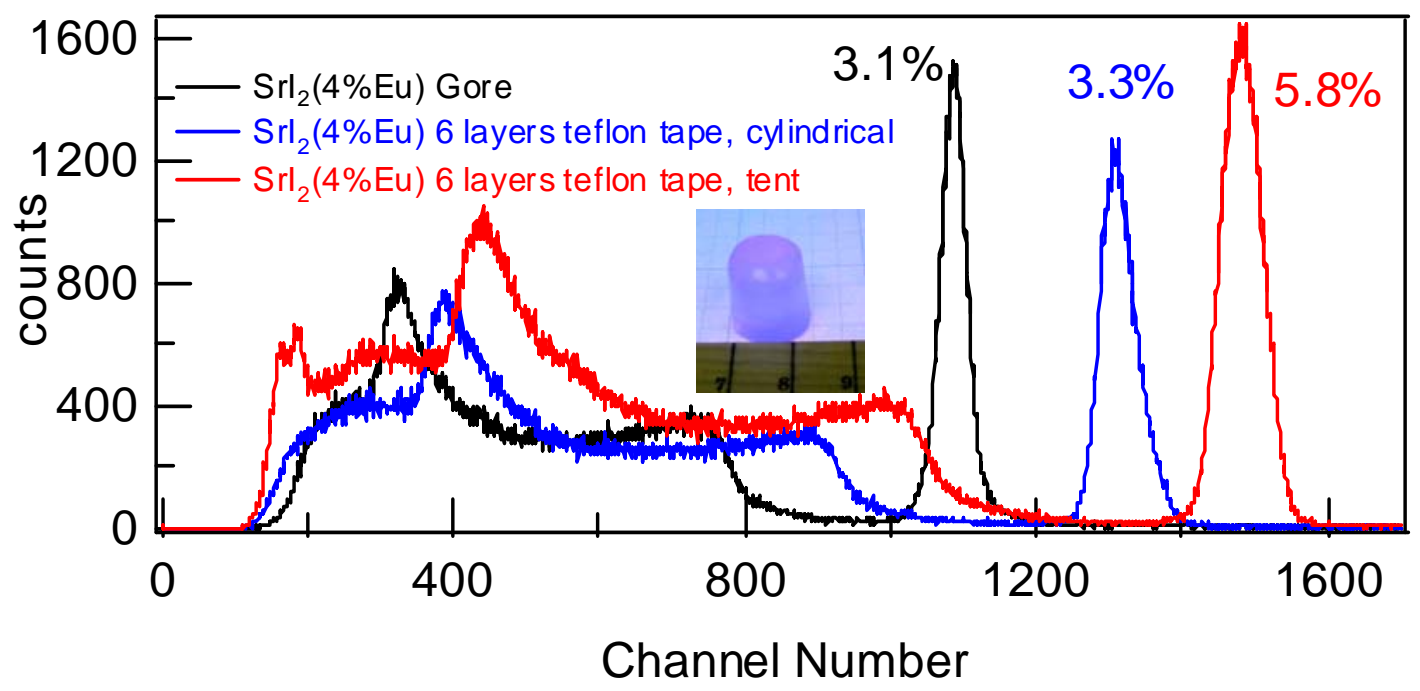

Figure 4. Cs-137 gamma ray (662 keV) pulse height spectra obtained with a $\mathrm{SrI}_{2}(4 \% \mathrm{Eu})$ crystal grown at ORNL from feedstock that was zone refined at Fisk University. Signals were collected from the PMT anode with a Bridgeport Instruments eMorpho digitizer. These data indicate that reflectivity and uniformity of wrapping are important considerations for achieving high resolution.

Crystal growth is easiest for cubic crystal structure types, while orthorhombic crystals exhibit modest anisotropy, resulting in crystal growth which is only slightly more subject to orientation dependent differential thermal expansion and growth kinetics than cubic structures. We have found that $\mathrm{SrI}_{2}$ is not prone to cracking or cleaving, and it is easily ground and polished. So far, the largest single crystal boule $\left(>30 \mathrm{~cm}^{3}\right)$ has been grown by RMD, shown in Figure 5 . The growth of further large crystals and exploration of growth conditions is currently underway. 


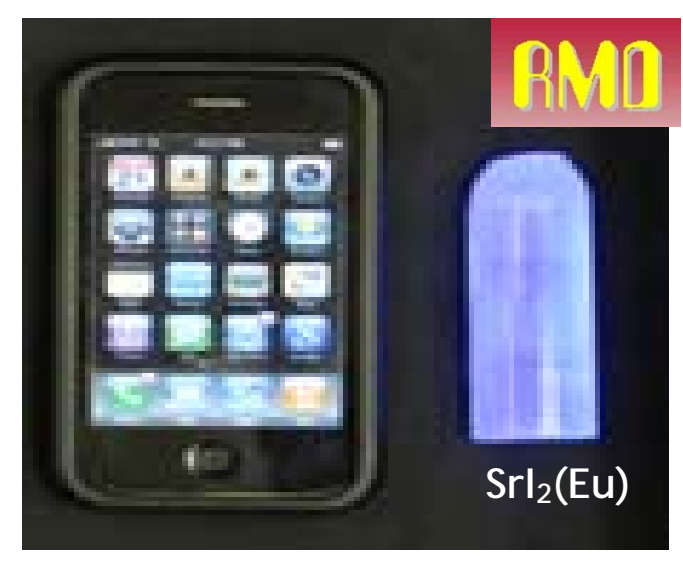

Figure 5. $\mathrm{A} \sim 30 \mathrm{~cm}^{3}$ single crystal of $\mathrm{SrI}_{2}(5 \% \mathrm{Eu})$, grown by RMD.

\section{CONCLUSION}

In summary, we find that strontium iodide crystals doped with europium provide energy resolution comparable to that of cerium doped lanthanum bromide scintillator crystals. The energy-dependent resolution of $\mathrm{SrI}_{2}(\mathrm{Eu})$ indicates that it will ultimately surpass the performance of $\mathrm{LaBr}_{3}(\mathrm{Ce})$, and is expected to reach $2.3 \%$ resolution at $662 \mathrm{keV}$ or better. Single crystal volumes of $\mathrm{SrI}_{2}(\mathrm{Eu})$ greater than $30 \mathrm{~cm}^{3}$ have been grown, thus the scale-up to large homogenous volumes needed for many scintillation counting applications is expected to be achievable.

\section{ACKNOWLEDGMENTS}

This work was supported by the Domestic Nuclear Detection Office in the Department of Homeland Security (Alan Janos) and performed under the auspices of the U.S. DOE by Lawrence Livermore National Laboratory under Contract DE-AC52-07NA27344. Oak Ridge National Laboratory is managed for the U.S DOE by UT-Battelle under contract DE-AC0500 OR22725.

\section{REFERENCES}

1. R. Hofstadter, E. W. O’Dell, and S. T. Schmidt, IEEE Trans. Nucl. Sci. NS-11, p. 12 (1964).

2. R. Hofstadter, "Europium-activated Strontium Iodide Scintillators," US Patent 3,373,279, (1968).

3. N.J. Cherepy, G. Hull, T.R. Niedermayr, A. Drobshoff, S.A. Payne, U.N. Roy, Y. Cui, A. Bhattacharaya, M. Harrison, M. Guo, M. Groza, A. Burger, "Barium iodide single-crystal scintillator detectors,” Proc. SPIE, vol. 6706, p. 670616 (2007).

4. J. Selling, M.D. Birowosuto, P. Dorenbos, S. Schweizer, "Europium-doped barium halide scintillators for x-ray and $\gamma$-ray detections,” J. Appl. Phys., vol. 101, p.034901, (2007).

5. N.J. Cherepy, G. Hull, A. Drobshoff, S.A. Payne, E. van Loef, C. Wilson, K. Shah, U.N. Roy, A. Burger, L.A. Boatner, W-S Choong, W.W. Moses "Strontium and Barium Iodide High Light Yield Scintillators,” Appl. Phys. Lett. vol. 92, p. 083508, (2008). 
6. R. Hawrami, M. Groza, Y.Cui, A. Burger, M.D Aggarwal, N. Cherepy and S.A. Payne, " $\mathrm{SrI}_{2}$ a Novel Scintillator Crystal for Nuclear Isotope Identifiers," Proc. SPIE, Vol. 7079, 70790 (2008).

7. CM Wilson, EV Van Loef, J. Glodo, N. Cherepy, G. Hull, SA Payne, W.-S. Choong, WW Moses, KS Shah, "Strontium iodide scintillators for high energy resolution gamma ray spectroscopy,” Proc. SPIE, Vol. 7079, 707917, (2008).

8. NJ Cherepy, SA Payne, SJ Asztalos, G Hull, JD Kuntz, T Niedermayr, S Pimputkar, JJ Roberts, RD Sanner, TM Tillotson, E van Loef, CM Wilson, KS Shah, UN Roy, R Hawrami, A Burger, LA Boatner, W.-S. Choong, WW Moses, "Scintillators with Potential to Supersede Lanthanum Bromide,” IEEE Trans. Nucl. Sci. (in press).

9. E.V.D. van Loef, C.M. Wilson N.J. Cherepy, G. Hull, S.A. Payne, W- S. Choong, W.W. Moses, K.S. Shah, "Crystal Growth and Scintillation Properties of Strontium Iodide Scintillators”, IEEE Trans. Nucl. Sci. (in press).

10. G. Hull, S. Du, T. Niedermayr, S. Payne, N. Cherepy, A. Drobshoff, and L. Fabris "Light Collection Optimization in Scintillator Based Gamma-Ray Spectrometers,” Nucl. Instr. Meth. A, vol. 588, p. 384, 2008. 